\title{
The Application and Study of PBL Teaching Mode in Data Structure Course
}

\author{
Xu Yidan \\ Institute of Technology. East China Jiaotong University, Nanchang, Jiangxi, 330100, China
}

Keywords: PBL; data structure; teaching mode

\begin{abstract}
Among computer courses in most colleges and universities, data structure is the core contents of the teaching, and plays an obviously important role in the whole teaching process. In the long-term teaching of data structure course, the efficiency of teachers is relatively low, the learning of students is difficult, and the teaching method is obsolete and unique, which affects the learning of data structure course. How to innovate teaching methods and improve teaching level of data structure is the research project for teachers.
\end{abstract}

In the learning of computer related professional course, data structure is an important foundation course, and students can grasp basic theory of programming, learn editing program, master the operation systems and databases from the course. The content involved in the data structure is relatively complicated and abstract, and students may encounter certain difficulties in the study. In traditional cramming teaching method, students accept knowledge passively, which results in the unsatisfactory learning effects and declining leaning interests. At present, many colleges and universities are actively innovating teaching mode, and take PBL teaching method to increase the learning initiative of students, cultivate comprehensively the innovative, design, and abstract thinking capability of students, which is effective for the teaching of data structure course.

\section{Problems in Current Teaching of Data Structure Course}

\subsection{Problems in teaching process of teachers}

In the learning of computer courses, students are firstly required to learn systematically computer language, and then data structure. However, in the actual teaching, teacher in data structure course and computer language course is not the same one, and they lack effective communication, teacher of data structure cannot arrange teaching progress due to the insufficient understanding of actual grasp of computer language, which also brings difficulties to students in their learning attitude. Many teachers cannot fully focus on key points and difficulty points to teach in data structure because of insufficient experience, thus students cannot deeply understand the importance of data structure, and cannot programme with knowledge of data structure, always in passive status. In addition, many teachers cannot fully consider characteristics of students, with rapid teaching speed and excessive application of multi-media, and questions for students are only about simple editing source code, ignoring the cultivation of creativity.

\subsection{Problems in the learning of students}

At present, most colleges and universities generally teach C-language programming before the teaching of data structure in the beginning of entry of colleges and universities ${ }^{[1]}$. Whereas, many students did not learn computer language in secondary school, think that C-language is abstract and difficult, and cannot find solutions when encountering problems in programming. Besides, students lack the spirit of independent learning, are not careful in the learning and cannot solve problems timely, and the phenomenon of copying experimental report always occurs, which leads to unsatisfactory learning effects.

\section{Basic Concept of PBL Teaching Mode}

PBL is the English abbreviation of problem-based learning, and it is a student-centered 
innovative teaching model. The PBL teaching model was founded in 1969 by the American professor of theology, Barrows at McMaster University, which is a mainstream teaching method applied by many colleges and universities today, and has played a very significant role in the teaching process.

PBL teaching is an innovation of traditional teaching methods. Traditional teaching methods are based on books and teachers, and students learn knowledge passively. Whereas, the PBL teaching method emphasizes the active learning of students, mobilizes the enthusiasm of students' learning through various methods, guides students' learning through the setting of questions, and enables students to acquire knowledge in the process of solving problems. In the process of teaching, teachers interpenetrate the content of learning into various problem situations. Students can solve related problems through independent thinking and cooperation with each other. In the process of thinking, students also acquire knowledge points and cultivate the ability to think independently and communicate and collaborate. In PBL mode, students are the main body of learning, teachers play the role of guiding and controlling, and the key is to cultivate the comprehensive ability of students.

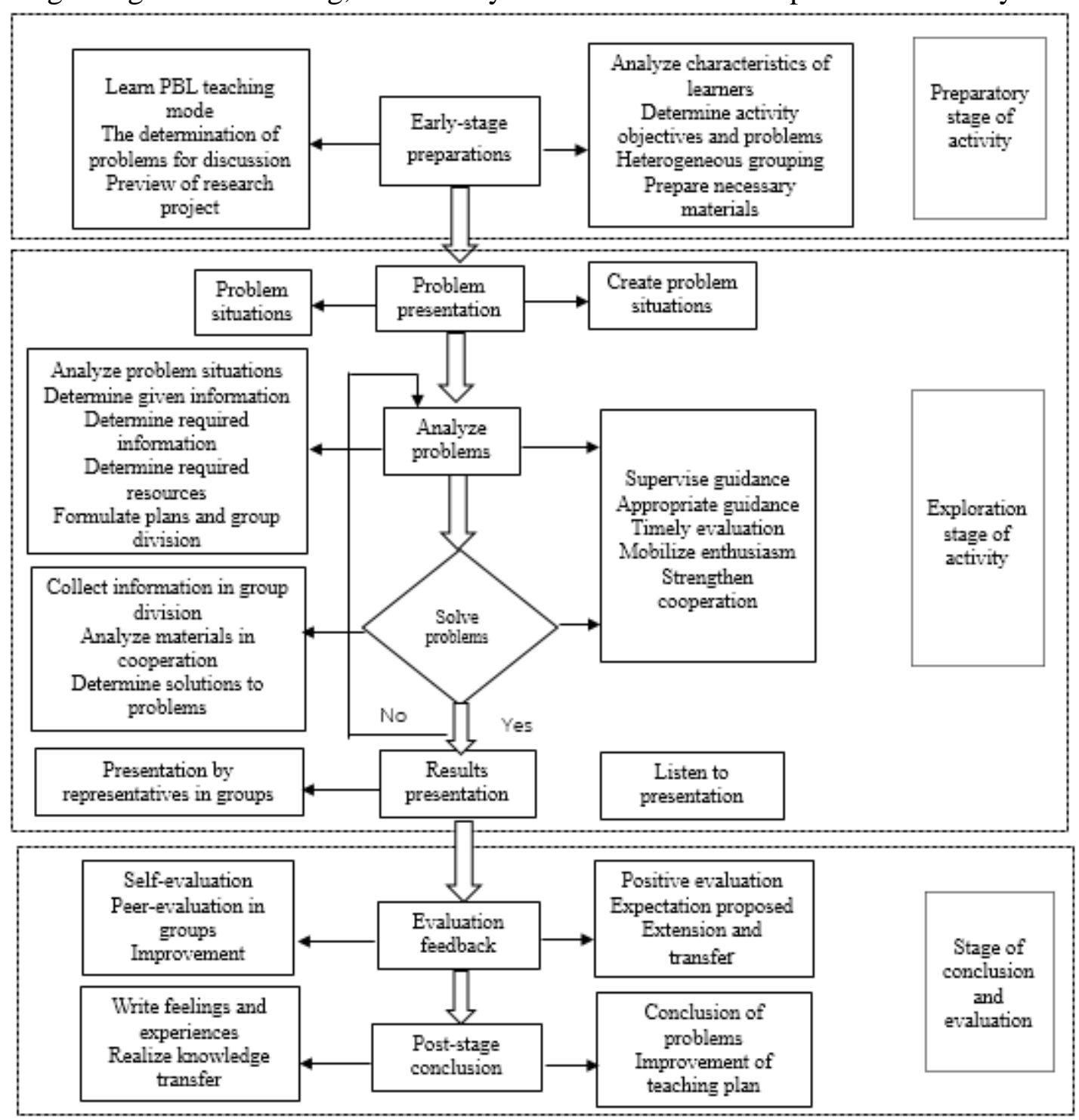

Figure 1 PBL teaching mode

The core of the PBL teaching mode is the design of problems, and the learning points are connected through different problems. In the process of designing problems, teachers need to fully consider the actual situation, consider the practical problems that students may encounter as a standard, and pay attention to evaluate the process of solving problems. Self-learning is combined with group discussion to develop the ability to work together in teamwork and thinking 
independently. After each problem is solved, students must conduct self-evaluations and identify their strengths and weaknesses in the discussion. Figure 1 is the flow diagram of the PBL teaching mode. The general process is the teacher puts forward relevant questions, students think about solving problems, students conduct group discussions, and finally teachers summarize ${ }^{[2]}$.

As a novel teaching mode, PBL puts forward new requirements for teachers and students. For teachers, it is necessary to be proficient in professional knowledge, grasp the ability to apply knowledge and solve problems, and also learn to design problems in classrooms, effectively organize classroom learning, control the rhythm of teaching, highlight the teaching focus, and guide students to fully learn relevant knowledge through lively activities. Students also are required to fully cooperate with teachers' teaching, prepare for the content of the class in advance, think positively about the questions raised by teachers, refer to relevant materials, communicate with classmates more, improve the initiative of learning, and truly become masters of learning.

\section{The Application of PBL Teaching Mode in Data Structure Course}

\subsection{Preparations in early stage for teachers}

PBL teaching mode can be applied to the teaching of data structure, taking maze solving course as an example.

Time for each class is relatively limited, therefore, teachers need to make adequate preparations in order to make full use of class time to achieve teaching effects. The curriculum of data structure is relatively abstract and logical, and the relationship between various data structures is very complex, which requires teachers to use scientific teaching methods to enable students to understand correctly. The PBL teaching model puts forward new and higher requirements for teachers. Teachers no longer just indoctrinate teaching materials, but need to further explore the teaching content, and process and refine the knowledge points and difficult points involved in the curriculum content to design problems, allowing students to think independently and have free discussion in class. At the same time, teachers should combine actual conditions of students, fully analyze the characteristics of students, design problems according to the actual situation of students' learning, prepare appropriate reference materials, and formulate reasonable evaluation standards. Students should conduct preparations before class according to the questions and relevant information provided by teachers ${ }^{[3]}$.

\subsection{The process of specific classroom teaching}

The setting of problem situations in PBL teaching mode needs to propose problems reasonably, fully attract learning interest and thirst for knowledge of students, guide students into problem situations, and consider actual learning competence of students with moderate difficulties, and answers of questions shall be open-ended to guide students to solve problems in discussion.

Stack and queue are two important basic structures in data structure with the characteristics of different operating modes and constrained conditions. The teaching simply relying on materials is abstract and it is difficult for students to understand. The teacher can use a stack of books to visualize the explanation. The concept of the stack is the same as the box that holds the stack of books. The first book that is put in the box can only be taken out at the end. If the new book is to be placed in the box, it can only be put in from the top, which vividly describes the basic principle of first-in last-out in teaching materials. However, queue is different. Just like lining up for tickets, people who come first buy first, and those who come later will need to wait at the end of the queue, which is called first-in first-out. In this way, the two abstract concepts of stack and queue are visualized to allow students to have a clearer understanding. After the above explanation, the teacher can introduce well-designed relevant problems of maze solving for students to find solutions, and learn similar problem algorithms to maze solving. Teachers shall conclude based on problems exposed in the learning process in a timely manner, and point out knowledge points mainly required to be grasped. The group discussion of students is mainly to analyze which kind of data structure is suitable for the maze solving problem, how to accurately determine the road and 
the current position, avoid wasting time on the impassable road, and find the shortest path out of the maze. After student solves these problems, teachers give guidance, which is very helpful for students to master the knowledge ${ }^{[4]}$.

PBL classroom teaching mode is a process of posing problems and solving problems, which is mainly finished by students themselves. Through group discussion and independent thinking, students can discover and actively solve new problems. With the learning of stack and queue, students can apply proficiently knowledge and enhance the innovative ability and teamwork spirit. In class, teachers need to pay close attention to learning status of each student and the specific situation of each group discussion, and guide each group to actively explore issues. For those students who have poor learning ability of computer language and programming ability, teachers are required to provide more guidance and attention. For some difficult problems, teachers should also give active guidance to students' ways of thinking and solving problems, and guide students to use different methods to solve problems.

\subsection{The evaluation and conclusion of teaching results}

After the problems are solved through thinking and group discussion, teachers need to arrange students to demonstrate the programming results on computer, one representative of each group to present basic programming thinking to solve problems in discussion, which is the key points. According to presentation of students, teachers give evaluation to design results of specific programming and algorithm of each group, and solutions to problems. Peer evaluation can also be conducted between groups to increase the opportunities of communication, enrich students' solution thinking and they can learn from each other. Teachers shall provide more encouragement for students, correct problems in time to avoid the reoccurring of same problems. Meanwhile, teachers formulate evaluation standards in advance to evaluate objectively students based on classroom performance, participation in group discussion, innovative thinking and ability of communication and cooperation.

In addition to classroom teaching, the conclusion in post stage is also very important. Teachers must consolidate what students have learnt in a timely manner and guide students to think in depth, for example, the specific applications of stack and queue in real life, aspects of the algorithm required to be improved, and methods to rationally use relevant concepts of time and space in maze solving problems, encourage students summarize the significance of their own problem-solving process in their professional knowledge learning and research in the future, which requires students to write written materials, and teachers to assess, identify problems timely, and constantly innovate ideas and improve teaching plans ${ }^{[6]}$.

\subsection{Other application examples}

Many teachers think that the teaching key points in data structure is graph, tree and linear list, main difficulties are the understanding and application of relatively abstract recursive algorithm, and the introduction of PBL mode has beneficial effects in solving these problems.

In the teaching of recursive algorithm, the effects of the combination of PBL teaching mode and traditional teaching mode are obvious. For instance, a teacher from certain college provides problems.

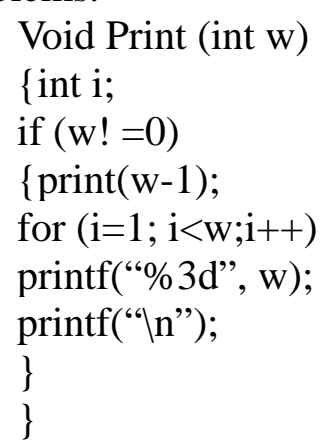

Where, $\mathrm{w}=4$.

According to problems, teachers group students for discussion, fully consider specific learning 
competence of students, collocate students with high and low learning grades, and determine the number of groups based on the number of students. In the group discussion, students can freely talk and raise questions at any time, and conclude answers after discussion, which may not be correct, however, the learning enthusiasm of students have been enhanced dramatically, and questions also been clarified in discussion. The conclusion of teachers after discussion indicates that the presentation of recursive algorithm with tree diagram is easier for students to understand and solve problems. Besides, teachers also can introduce Tower of Hanoi to lay a foundation for the learning of students in the future. With PBL teaching mode, students can understand recursive algorithm more deeply and improve their own learning competence of computer. Since the C-language program is run in a certain order because of its own characteristics, it is easy to draw a result with a tree diagram, shown in Figure $2^{[7]}$.

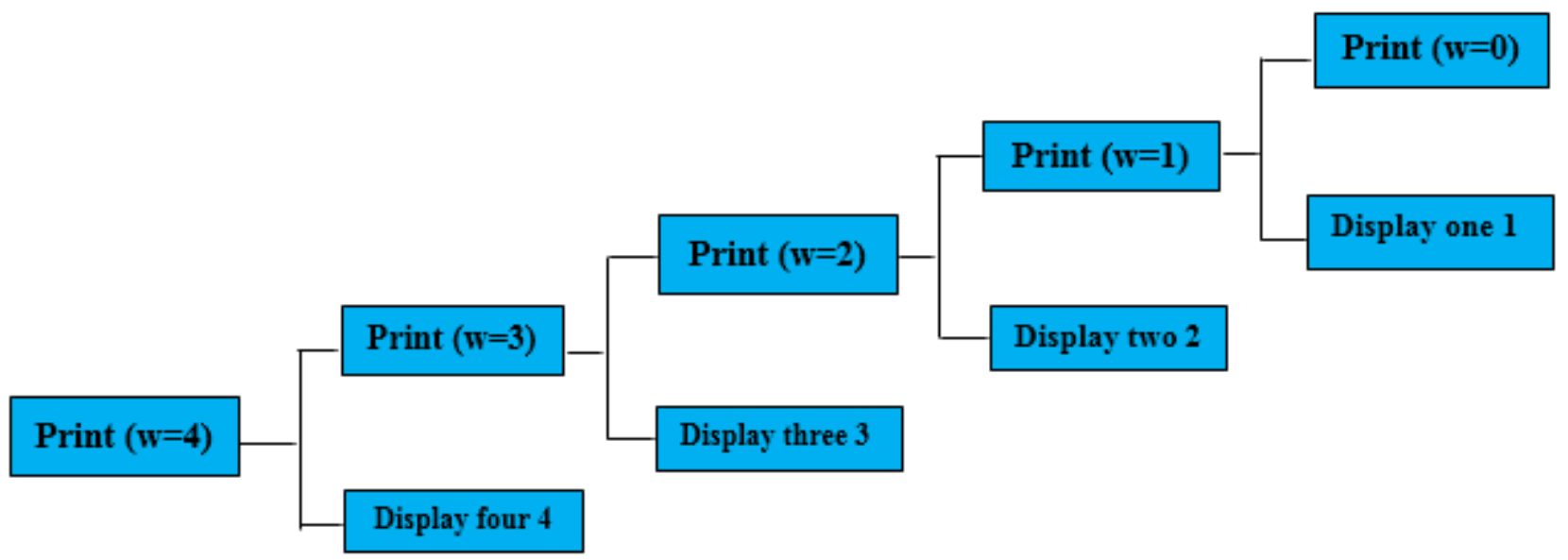

Figure 2

It can been seen that, in the learning of programming design and specific practice of data structure course, the reasonable application of PBL teaching mode plays an important role in knowledge grasp and capability strengthening of students, improving the teaching efficiency of teachers in class, and enhancing the learning competence of students.

\section{Conclusion:}

With the continuous development of science and technology, the requirements of professional talents in computer are increasing, which also requires relevant teachers to actively conduct teaching reform and improve the professional competence of computer talents. PBL teaching method changes classroom teaching mode to be student-centered and problem-based, cultivates incessantly the ability of independent learning and teamwork cooperation, stimulate learning interests of students, and cultivates the comprehensive competence of students, which is worthy of promoting. Colleges and universities shall innovate teaching modes according to actual situations to strive for cultivating more professional talents.

\section{Acknowledgements}

Funding Project: This paper is from the research project of teaching reform in colleges and universities of Jiangxi Province, the Application and Study of PBL Teaching Mode in Data Structure Course. Project No. JXJG-17-35-5.

\section{References}

[1] Xu Mingyang, Wang Yingzhan. Exploration of Teaching Modes of Data Structure Course in Higher Vocational Colleges [J]. Science\& Technology Vision, 2012(19):145-146.

[2] Li Lixia. Teaching Practice of Data Structure in PBL Mode [J]. Fujian Computer, 2011, 
27(05):193-194+210.

[3] Bu Hui, Liu Ran. Application of Inquiring Learning Teaching Mode in Data Structure Course [J]. Computer Knowledge and Technology, 2011, 7(03):583-585.

[4] Guo Qun. Study on Teaching Mode Reform in Data Structure Course Based on “Applied Undergraduate Talent Cultivation Objective” [J]. Propagation and Copyright, 2015(06):132-133.

[5] Shen Hua, Zhang Mingwu, Xie Haitao. Exploration of Applied Teaching Mode of Data Structure Course [J]. Computer Education, 2016(05):59-62.

[6] Feng Hongcai, Xia Xiangsheng, Zuo Cuihua. Exploration and Practice of the Teaching Model of Independent Research about Course Experiment of "Data Structure" [J]. Computer Education, 2011(06):73-76.

[7] Mao Shengli, Feng Yuanfang, Cheng Xicai, Liu Zhiyuan. Research and Discussion on Teaching Model of Data Structure Based on PBL [J]. Modern Computer, 2015(25):10-13. 